\title{
Photoassisted Synthesis of CdSe and Core-Shell CdSe/CdS Quantum Dots
}

\author{
Yang-Wei Lin, ${ }^{\dagger}$ Ming-Mu Hsieh, $\stackrel{\ddagger}{\dagger}$ Ching-Piao Liu ${ }^{\S}$ and Huan-Tsung Chang* ${ }^{\dagger}$ \\ Department of Chemistry and Department of Agricultural Chemistry, \\ National Taiwan University, Section 4, Roosevelt Road, Taipei, Taiwan, and \\ Department of Applied Chemistry, Fooyin University, Kaohsiung, Taiwan
}

Received February 27, 2004. In Final Form: October 30, 2004

\begin{abstract}
This paper describes the synthesis of core-shell CdSe/CdS quantum dots (QDs) in aqueous solution by a simple photoassisted method. CdSe was prepared from cadmium nitrate and 1,1-dimethylselenourea precursors under illumination for up to $3 \mathrm{~h}$ using a pulsed Nd:YAG laser at $532 \mathrm{~nm}$. The effects that the temperature and the laser irradiation process have on the synthesis of CdSe were monitored by a series of experiments using the precursors at a Cd:Se concentration ratio of 4 . Upon increasing the temperature $\left(80-140{ }^{\circ} \mathrm{C}\right)$, the size of the CdSe QDs increases and the time required for reaching a maximum photoluminescence (PL) is shortened. Although the as-prepared CdSe QDs possess greater quantum yields (up to $0.072 \%$ ) compared to those obtained by microwave heating $(0.016 \%$ ), they still fluoresce only weakly. After passivation of CdSe (prepared at $80^{\circ} \mathrm{C}$ ) by CdS using thioacetamide as the S source (Se:S concentration ratio of 1 ) at $80^{\circ} \mathrm{C}$ for $24 \mathrm{~h}$, the quantum yield of the core-shell CdSe/CdS QDs at $603 \mathrm{~nm}$ is $2.4 \%$. Under UV irradiation of CdSe/CdS for $24 \mathrm{~h}$ using a 100-W Hg-Xe lamp, the maximum quantum yield of the stable QDs is $60 \%$ at $589 \mathrm{~nm}$. A small bandwidth $\left(W_{1 / 2}<35 \mathrm{~nm}\right)$ indicates the narrow size distribution of the as-prepared core-shell CdSe/CdS QDs. This simple photoassisted method also allows the preparation of differently sized (3.7-6.3-nm diameters) core-shell CdSe/CdS QDs that emit in a wide range (from green to red) when excited at $480 \mathrm{~nm}$.
\end{abstract}

\section{Introduction}

Semiconductor nanoparticles or quantum dots (QDs) exhibit quantum-size dependence of their electrical and optical properties and have attracted great fundamental and applied attention over the past decade. ${ }^{1-7}$ For example, differently sized QDs of $\mathrm{CdE}(\mathrm{E}=\mathrm{S}, \mathrm{Se}$, or $\mathrm{Tl})$ that are prepared under different conditions (e.g., temperature, reaction time, capping agent, and ratio of $\mathrm{Cd} / \mathrm{E}$ ) can emit from blue to red when excited at the same wavelength. ${ }^{8-11}$ In addition, CdE QDs provide advantages over organic fluorophores, including chemical stability, high photobleaching threshold, and narrow emission spectra. ${ }^{12-14}$ Therefore, CdE QDs have become one of the most important sensing materials for a great number of

* Address correspondence to this author. Phone: 011-886-223621963.Fax: 011-886-2-23621963.E-mail: changht@ntu.edu.tw.

Department of Chemistry, National Taiwan University.

$\doteqdot$ Department of Applied Chemistry, Fooyin University.

$\S$ Department of Agriculture Chemistry, National Taiwan University.

(1) Murphy, C. J. Anal. Chem. 2002, 74, 520 A.

(2) Nirmal, M.; Brus, L. Acc. Chem. Res. 1999, 32, 407.

(3) Alivisatos, A. P. Science 1996, 271, 933.

(4) Brus, L. E. J. Chem. Phys. 1986, 90, 2555.

(5) Peng, X. G.; Wickham, J.; Alivisatos, A. P. J. Am. Chem. Soc. 1998, 120,5343

(6) Murray, C. B.; Norris, D. J.; Bawendi, M. G. J. Am. Chem. Soc. 1993, 115,8706 .

(7) Brennan, J. G.; Siegrist, T.; Carroll, P. J.; Stucczynski, S. M.; Reynders, P.; Brus, L. E.; Steigerwald, M. L. Chem. Mater. 1990, 2, 403.

(8) Murase, Y.; Ota, T.; Yasui, N.; Shikimi, A.; Noma, T.; Maehashi,

K.; Nakashima, H. J. Cryst. Growth 2000, 214/215, 770.

(9) Qu, L.; Peng, X. J. Am. Chem. Soc. 2002, 124, 2049.

(10) Wang, T.; Herron, N. J. Phys. Chem. 1991, 95, 525.

(11) Hao, E.; Sun, H.; Zhou, Z.; Liu, J.; Yang, B.; Shen, J. Chem. Mater. 1999, 11, 3096.

(12) Tran, P. T.; Goldman, E. R.; Anderson, G. P.; Mauro, J. M.; Mattoussi, H. Phys. Status Solidi B 2002, 229, 427.

(13) Bruchez, M., Jr.; Moronne, M.; Gin, P.; Weiss, S.; Alivisatos, A. P. Science 1998, 281, 2013.

(14) Chan, W. C. W.; Nie, S. Science 1998, 281, 2016. interesting biological analytes, including proteins, ${ }^{15,16}$ DNA, ${ }^{17,18}$ and metal ions. ${ }^{19}$

CdSe QDs have broad absorption spectra, with a first absorption peak (band edge) and emission profiles that span a wide range of wavelengths in the visible region, both of which shift to longer wavelengths upon increasing the particle size. The various sizes of CdSe QDs that provide such interesting optical properties can be prepared in either aqueous or organic solutions. In the presence of organic surfactants, such as trioctylphosphine oxide (TOPO) and tributylphosphine (TBP), CdSe QDs synthesized at high temperature possess narrow size distributions. ${ }^{6,7}$ Typical values of the full width at half-maximum (fwhm) of the photoluminescence (PL) peak and the QY of the as-prepared CdSe QDs are 27-40 nm and $<20 \%$, respectively. Recently, CdSe QDs have been prepared from $\mathrm{CdO}$ and Se powder in the presence of stearic acid, TOPO, and hexadecylamine in a very narrow size distribution (relative standard distribution: 5-10\%), narrow fwhm (ca. $23 \mathrm{~nm}$ ), and high QY (up to $85 \%$ at room temperature). ${ }^{9}$ The solubility of as-prepared CdSe QDs in aqueous solution is poor, however, which limits their biological applications. To improve their solubility, these QDs generally are subjected to solvent exchange with watersoluble reagents, such as mercaptoacetic acid and mercaptodecanoic acid. Great attention must be paid, however,

(15) Mattoussi, H.; Mauro, J. M.; Goldman, E. R.; Green, T. M. Anderson, G. P.; Sundar, V. C.; Bawendi, M. G. Phys. Status Solidi B 2001, 224, 277

(16) Chen, Y.; Ji, T.; Rosenzweig, Z. Nano Lett. 2003, 3, 581.

(17) Parak, W. J.; Gerion, D.; Zanchet, D.; Woerz, A. S.; Pellegrino, T.; Micheel, C.; Williams, S. C.; Seitz, M.; Bruehl, R. E.; Bryant, Z.; Bustamante, C.; Bertozzi, C. R.; Alivisatos, A. P. Chem. Mater. 2002, $14,2113$.

(18) Pathak, S.; Choi, S.-K.; Arnheim, N.; Thompson, M. E. J. Am. Chem. Soc. 2001, 123, 4103.

(19) Chen, Y.; Rosenzweig, Z. Anal. Chem. 2002, 74, 5132. 
to minimize deterioration of the PL of CdSe QDs because it is highly sensitive to the surface properties. ${ }^{20}$

There are several different strategies for the preparation of CdSe QDs in aqueous solution. ${ }^{21-23}$ To stabilize CdSe QDs, either citrate or a thiol compound, such as thioglycerol, is commonly added to the solution. Although conventional methods of QD synthesis are conducted under reflux, the synthesis of CdSe QDs using cadmium perchlorate and 1,1-dimethylselenourea at pH 9.0 has been demonstrated also in a conventional microwave oven $(900$ W) ${ }^{24}$ This approach is probably the simplest and quickest (50 s) one for preparing water-soluble CdSe QDs; however, although it allows the synthesis of various-sized CdSe QDs by carefully controlling the Cd:Se ratio, these QDs possess very low values of $Q Y(0.1-0.15 \%$ in comparison with rhodamine $6 \mathrm{G})$, large values of fwhm $(>45 \mathrm{~nm})$, and surface instability when exposed to light and air. These shortages are associated with polydispersity in size and shape as well as with the presence of many surface electronic defects, such as surface nonstoichiometry and unsaturated bonds, which act as nonradiative recombination or irradiative PL centers.

To extend the applications of QDs, organic and inorganic compounds have been used to passivate the surface and, consequently, to improve the PL properties, such as QY and photostability. ${ }^{25-28}$ Compared to the use of organic capping materials, inorganic epitaxial growth is able to eliminate both anionic and cationic surface dangling bonds and to generate core-shell systems, such as CdSe/CdS QDs, that have novel properties, for example, greater stability and PL QY, depending on the nature of both the core and shell materials. Alternatively, exposure of freshly prepared CdSe or CdSe/CdS QDs to ambient light, UV light, or laser irradiation can lead to over a 100-fold improvement in the PL QY..$^{29,30}$

This paper presents a simple synthetic route for the production of high-quality CdSe QDs. With the assistance of laser irradiation at $532 \mathrm{~nm}$, this simple approach allows the preparation CdSe QDs possessing greater PL QY and narrower values of fwhm when compared with those prepared by microwave heating. By controlling the Cd:Se concentration ratio, this approach allows the synthesis of variably sized CdSe QDs. We passivated these CdSe QDs further with thioacetamide to yield as-prepared coreshell CdSe/CdS QDs that vary from 3.7 to $6.3 \mathrm{~nm}$ in diameter and emit green to red. After UV irradiation for $24 \mathrm{~h}$, the PL QY for the core-shell CdSe/CdS QDs further improved, up to a maximum value of $60 \%$.

\section{Experimental Section}

Cadmium nitrate, 1,1-dimethylselenourea, thioacetamide, sodium citrate, and sodium hydroxide were obtained from Aldrich (Milwaukee, WI). Milli-Q ultrapure water was used in all experiments.

(20) Nazzal, A. Y · Qu, L.; Peng, X : Xiao, M. Nano Lett. 2003, 3, 819

(21) Rajh, T.; Micic, O. I.; Nozik, A. J. J. Phys. Chem. 1993, 97, 11999.

(22) Lee, G. S. H.; Craig, D. C.; Ma, I.; Scudder, M. L.; Bailey, T. D.;

Dance, I. G. J. Am. Chem. Soc. 1988, 110, 4863.

(23) Herron, N.; Calabrese, J. C.; Fameth, W. E.; Wang, Y. Science 1993, 259,1426

(24) Rogach, A. L.; Nagesha, D.; Ostrander, J. W.; Giersig, M.; Kotovpp, N. A. Chem. Mater. 2000, 12, 2676.

(25) Xu, L.; Wang, L.; Huang, X.; Zhu, J.; Chen, H.; Chen, K. Physica E 2000, 8, 129 .

(26) Tain, Y.; Newton, T.; Koov, N. A.; Guldi, D. M.; Fendler, J. J. Chem. Phys. 1996, 100, 8927.

(27) Danek, M.; Jensen, K. F.; Murray, C. B.; Bawendi, M. G. Chem. Mater. 1996, 8,173 .

(28) Myung, N.; Bae, Y.; Bard, A. J. Nano Lett. 2003, 3, 747.

(29) Wang, Y.; Tang, Z.; Correa-Duarte, M. A.; Liz-Marzán, L. M.; Kotov, N. A. J. Am. Chem. Soc. 2003, 125, 2830.

(30) Cordero, S. R.; Carson, P. J.; Estabrook, R. A.; Strouse, G. F.; Buratto, S. K. J. Phys. Chem. B 2000, 104, 12137.

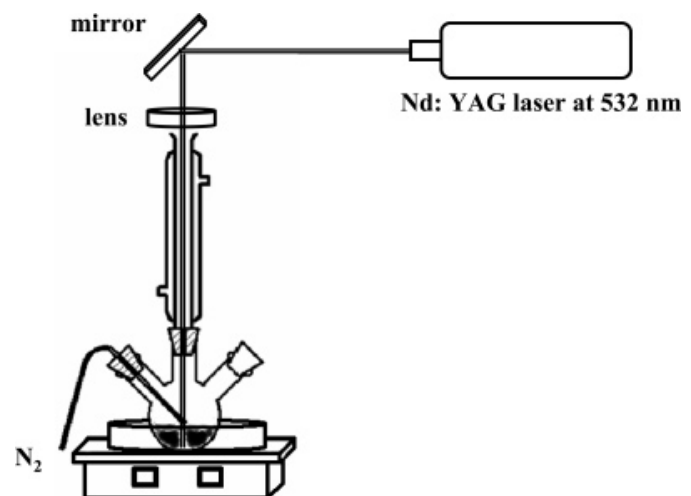

Figure 1. Schematic depiction of the setup used for the laserassisted synthesis of CdSe QDs in aqueous solution.

Preparation of Citrate-Stabilized CdSe QDs. Stock solutions of $40 \mathrm{mM}$ cadmium ions and $10 \mathrm{mM}$ selenium ions were prepared by dissolving cadmium nitrate $(1.23 \mathrm{~g})$ and 1,1 dimethylselenourea $(0.16 \mathrm{~g})$ separately in water $(100 \mathrm{~mL}$ each $)$. Aliquots of $40 \mathrm{mM}$ cadmium nitrate $(1-6 \mathrm{~mL})$ were added to round-bottom flasks containing $7.5 \times 10^{-3} \mathrm{M}$ aqueous sodium citrate solutions $(46-41 \mathrm{~mL})$. The mixtures were adjusted to $\mathrm{pH}$ 9.0 with $0.1 \mathrm{M} \mathrm{NaOH}$ and then nitrogen gas was bubbled through them for $10 \mathrm{~min}$ prior to the addition of $10 \mathrm{mM}$ 1,1-dimethylselenourea $(2 \mathrm{~mL})$; the final molar ratios of Cd:Se ranged from 2 to 12 . The mixtures were then gently stirred under a $\mathrm{N}_{2}$ atmosphere $\left(5 \mathrm{~kg} / \mathrm{cm}^{2}\right.$; flow rate: $\left.0.03 \mathrm{~L} / \mathrm{min}\right)$ and heated in a silicon oil bath for $0-3 \mathrm{~h}$ at temperatures in the range from 60 to $140^{\circ} \mathrm{C}$ while they were illuminated (Figure 1) at $532 \mathrm{~nm}$ under irradiation from an Nd:YAG laser (Continuum; model: EPO5000; Santa Clara, CA) having a $3000-\mathrm{Hz}$ output $(50 \mathrm{~mW})$. To investigate the effect that the laser power has on the synthesis of the CdSe nanoparticles, we also used diode-pumped solidstate green lasers (Lasermate Group, Inc; model: GMF-532; Pomona, CA) having outputs of 15,50 , and $100 \mathrm{~mW}$. A mirror and a double-convex lens (A33-502 and A45-171, respectively; Edmund Industrial Optics, Barrington, U.S.) were used to direct and focus (spot size: $2 \mathrm{~cm}$ ) the laser light at the centers of the round-bottom flasks.

Preparation of Core-Shell CdSe/CdS QDs. Aliquots of 40 $\mathrm{mM}$ thioacetamide $(0.5 \mathrm{~mL})$ as a sulfur source were added separately to the as-prepared CdSe QDs $(50 \mathrm{~mL})$ to maintain a constant S:Se molar ratio of 1 . The mixtures, in sealed roundbottom flasks, were heated in a silicon oil bath at $70-80^{\circ} \mathrm{C}$ under a $\mathrm{N}_{2}$ atmosphere for certain times of up to $24 \mathrm{~h}$. As the reaction proceeded, the colors of the solutions changed, indicating the formation of the CdS shell.

Photopassivation of Core-Shell CdSe/CdS QDs. The asprepared core-shell $\mathrm{CdSe} / \mathrm{CdS}$ QDs were gently stirred at ambient temperature $\left(25{ }^{\circ} \mathrm{C}\right)$ while being illuminated for $24 \mathrm{~h}$ with a 100-W Xe-Hg lamp (model: L 2442; Hamamatsu Photonics K. K., Shizuoka-Ken, Japan). During their illumination, the vials containing the core-shell CdSe/CdS QDs were sealed to avoid any loss of the solutions as a result of vaporization.

Characterization of CdSe and CdSe/CdS QDs. The UVvis absorption and fluorescence of the as-prepared QDs were recorded using a double-beam UV-vis spectrophotometer (Cintra 10e, GBC Scientific Equipment Pty Ltd, Dandenong, Victoria, Australia) and a fluorometer (Aminco-Bowman Series 2, ThermoSpectronic, Pitsford, NY), respectively. The QYs of the CdSe and CdSe/CdS QDs were determined by comparison with the value of the $\mathrm{QY}$ of rhodamine $6 \mathrm{G} .{ }^{31}$ The dimensions of the asprepared CdSe and CdSe/CdS QDs were measured using a JSM1200EX II (JEOL Ltd., Tokyo, Japan) transmission electron microscope (TEM). To confirm the contents of the elements of the as-prepared $\mathrm{CdSe}$ and core-shell $\mathrm{CdSe} / \mathrm{CdS} \mathrm{QDs}$, we conducted energy-dispersive X-ray (EDX) spectroscopy measurements using a LINK ISIS 300 spectrometer (Oxford Corp., U.K.) operating at $80 \mathrm{kV}$ and $\mathrm{WD}=20 \mathrm{~nm}$. X-ray powder diffraction (XRD) patterns were recorded using $\mathrm{Cu} \mathrm{K} \alpha$ radiation (model:

(31) Georges, J.; Arnaud, N.; Parise, L. Appl. Spectrosc. 1996, 50, 1505 


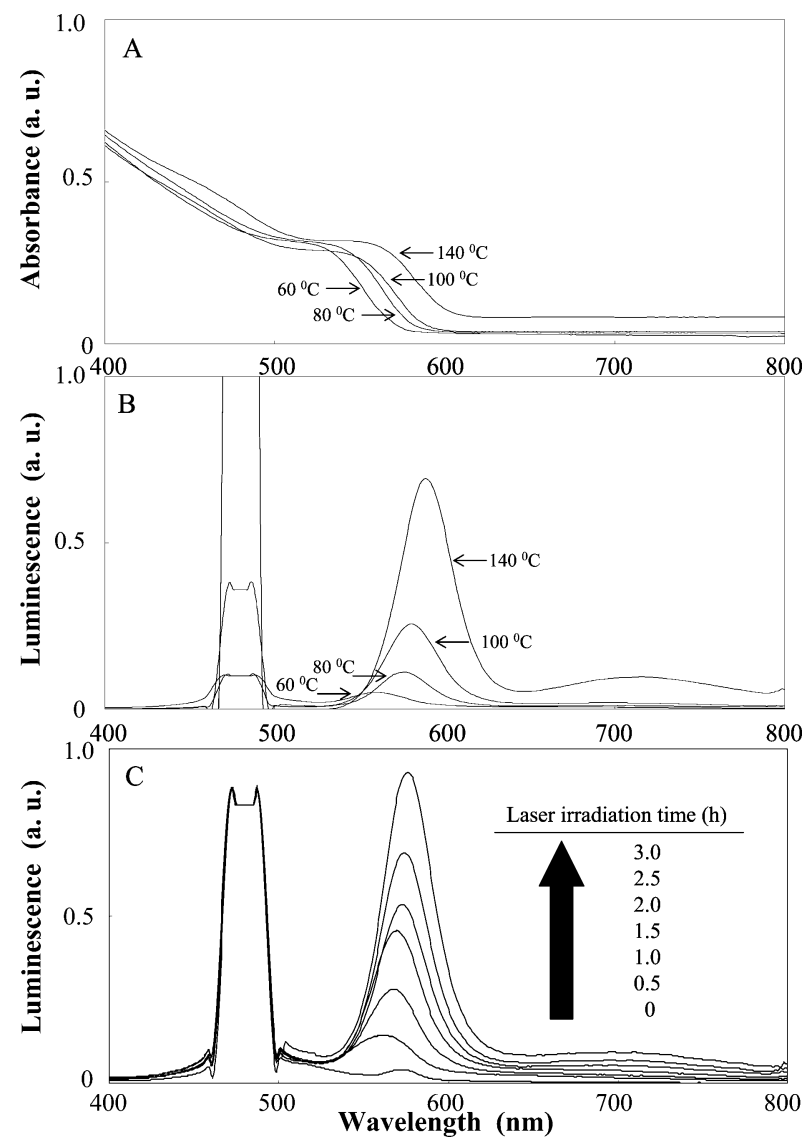

Figure 2. Effect of temperature and laser irradiation on the optical properties of the CdSe QDs. (A) Absorption edge; laser irradiation for $3 \mathrm{~h}$. (B) Effect of temperature on the emission (excited at $480 \mathrm{~nm}$ ); laser irradiation for $3 \mathrm{~h}$. (C) Time evolution of the emission (excited at $480 \mathrm{~nm}$ ) during laser irradiation at $80{ }^{\circ} \mathrm{C}$.

X'Pert Pro; PANalytical, Spectris plc, U.K.). The nanoparticles were placed on quartz glass prior to the XRD measurements.

\section{Results and Discussion}

Laser-Assisted Synthesis of CdSe QDs. Although microwave heating of cadmium perchlorate and 1,1dimethylselenourea in the presence of citrate is a rapid and easy method for the synthesis of fairly stable CdSe QDs, its main disadvantage is the low QYs of the as-prepared QDs $(<0.1-0.15 \%$ in comparison with rhodamine 6G). To overcome this shortcoming, we have developed a new method, namely, laser-assisted synthesis, for preparing CdSe QDs from cadmium nitrate and 1,1dimethylselenourea. Hereafter, we have investigated the roles that temperature and laser irradiation play in determining the optical properties of CdSe QDs by using the precursors at a Cd:Se molar ratio of 4 . At constant temperature, the intensities for the two emission bands that arise from band-edge emission (narrow blue band near $580 \mathrm{~nm}$ ) and the recombination of trapped charge carriers (broad red band near $720 \mathrm{~nm}$ ) both increase with irradiation time (not shown). ${ }^{32}$ Because the wavelengths of the absorption edge $(1 \mathrm{~s}-1 \mathrm{~s}$ electronic transition) and emission (excited at $480 \mathrm{~nm}$ ) increased as the particle sizes of the CdSe QDs increased, the results depicted in Figure $2 \mathrm{~A}$ and $2 \mathrm{~B}$ indicate that the particle sizes of the CdSe QDs increased upon increasing the synthesis temperature in the range from 60 to $140{ }^{\circ} \mathrm{C}$ while irradiating

(32) Kortan, R.; Hull, R.; Opila, R. L.; Bawendi, M. G.; Steigerwald, M. L.; Carroll, P. J.; Brus, L. E. J. Am. Chem. Soc. 1990, 112, 1327. with an Nd:YAG laser at $532 \mathrm{~nm}$ for $3 \mathrm{~h}$. The growth rate increases with increasing temperature. In this study, we denote the CdSe QDs prepared at $60,80,100$, and $140{ }^{\circ} \mathrm{C}$ as $\mathrm{CdSe}(60), \mathrm{CdSe}(80), \mathrm{CdSe}(100)$, and $\mathrm{CdSe}(140)$, respectively. At the same Cd:Se ratio (i.e., 4), the absorption wavelength maxima for the $\mathrm{CdSe}(60)$ and $\mathrm{CdSe}(80) \mathrm{QDs}$ are shorter, while those for $\mathrm{CdSe}(100)$ and $\mathrm{CdSe}(140)$ are longer, than that obtained for the sample synthesized under microwave heating. The QYs (Table 1) of the asprepared CdSe QDs [e.g., 0.44\% for CdSe(140)] are greater than that $(0.016 \%)$ of the CdSe QDs synthesized under microwave heating. The emission intensities recorded at $580 \mathrm{~nm}$ increase with increasing temperature, but they remain very weak (15 times weaker) in the absence of laser irradiation. Without heating, the emission intensity centered at $580 \mathrm{~nm}$ increases with increasing illumination time; a weak and broad emission band centered at 690 $\mathrm{nm}(600-785 \mathrm{~nm})$ appeared after laser irradiation for over $8 \mathrm{~h}$ at room temperature. These results suggest that thermal and photoillumination both play roles in determining the optical properties of the CdSe QDs. The fwhm values for $\mathrm{CdSe}(60), \mathrm{CdSe}(80), \mathrm{CdSe}(100)$, and $\mathrm{CdSe}(140)$ $(37,38,37$, and $37 \mathrm{~nm}$, respectively) indicate narrow size distributions that arise mainly as a result of photoetching under UV irradiation. It has been proposed that large particles absorb the laser light $(532 \mathrm{~nm})$ and become photoetched to form smaller ones until the irradiated photons are no longer absorbed by the nanoparticles as a result of the size quantization effect. ${ }^{33}$ The maximum wavelengths of the emission bands for $\mathrm{CdSe}(60)$, CdSe(80), CdSe(100), and CdSe(140) QDs are 561, 578, 582, and $590 \mathrm{~nm}$, respectively, which indicates that the sizes of the as-prepared CdSe QDs increase upon increasing the temperature. This effect is due mainly to greater solubility of CdSe at higher temperature and, thus, particle growth dominates over nucleation. The average diameters for the $\mathrm{CdSe}(60), \operatorname{CdSe}(80), \mathrm{CdSe}(100)$, and $\mathrm{CdSe}(140)$ QDs, which we estimated by analyzing the TEM images (not shown), are $3.0,3.5,3.6$, and $3.8 \mathrm{~nm}$, respectively. During the laser irradiation, the particle size first decreases (blue shift), with a smaller rate of decrease occurring at lower temperature, and then increases (red shift) gradually. As the reaction time increased, the ions that dissolved from some of the smaller-sized CdSe QDs grew onto other CdSe QDs to form larger-sized CdSe particles (i.e., an Ostwald ripening mechanism operated). Figure $2 \mathrm{C}$ depicts the time evolution of the emission intensity for $\mathrm{CdSe}(80)$ QDs and demonstrates that photoetching or photooxidation of the surface of the CdSe QDs dominates the growth of the nanoparticles ${ }^{34}$ during the first half-hour of the reaction before nanoparticle growth (red shift) takes control. ${ }^{6}$

Passivation of CdSe and Photoetching of CoreShell CdSe/CdS. As demonstrated above, the CdSe QDs synthesized by the laser-assisted synthetic approach do not have impressive QYs. It is generally considered that low PL QYs such as these result from surface states located in the band gap of the QDs that act as trapping states for the photogenerated charges. These surface-trapping states originate from the dangling bonds of some of the surface atoms. ${ }^{9,35}$ Inorganic capping of QDs by a shell material having a wider band gap is an effective method for improving their PL QY and photostability. ${ }^{24}$ For example,

(33) Torimoto, T.; Kontani, H.; Shibutani, Y.; Kuwabata, S.; Sakata T.; Mori, H.; Yoneyama, H. J. Phys. Chem. B 2001, 105, 6838.

(34) Spanhel, L.; Haase, M.; Weller, H.; Henglein, A. J. Am. Chem. Soc. 1987, 109, 5649 .

(35) Fu, H.; Zunger, A. Phys. Rev. B: Condens. Matter 1997, 56, 1496 
Table 1. Comparison of the PL QY for CdS and Core-Shell CdSe/CdS QDs Prepared under Different Conditions

\begin{tabular}{|c|c|c|c|c|c|c|c|c|c|c|c|c|}
\hline \multirow[b]{3}{*}{ time $(\mathrm{h})^{a}$} & \multicolumn{12}{|c|}{$\mathrm{QY}(\%)$} \\
\hline & \multicolumn{3}{|c|}{$60^{\circ} \mathrm{C}$} & \multicolumn{3}{|c|}{$80^{\circ} \mathrm{C}$} & \multicolumn{3}{|c|}{$100^{\circ} \mathrm{C}$} & \multicolumn{3}{|c|}{$140^{\circ} \mathrm{C}$} \\
\hline & $\overline{\mathrm{Cd} \mathrm{Se}}$ & $\mathrm{CdSe} / \mathrm{CdS}$ & $\overline{\mathrm{CdSe} / \mathrm{CdS}^{b}}$ & $\mathrm{Cd} \mathrm{Se}$ & CdSe/CdS & $\overline{\mathrm{CdSe} / \mathrm{CdS}^{b}}$ & $\overline{\mathrm{Cd} \mathrm{Se}}$ & $\mathrm{CdSe} / \mathrm{CdS}$ & $\overline{\mathrm{CdSe} / \mathrm{CdS}^{b}}$ & $\overline{\mathrm{Cd} \mathrm{Se}}$ & CdSe/CdS & $\mathrm{CdSe} \mathrm{CdS}^{b}$ \\
\hline 0.5 & 0.005 & 1.1 & 5.8 & 0.010 & 1.2 & 5.9 & 0.014 & 0.4 & 13 & 0.12 & 4.2 & 43 \\
\hline 1.0 & 0.010 & 1.4 & 14 & 0.021 & 1.7 & 26 & 0.023 & 0.8 & 15 & 0.16 & 5.0 & 45 \\
\hline 1.5 & 0.015 & 2.0 & 14 & 0.035 & 2.0 & 31 & 0.036 & 1.0 & 18 & 0.24 & 6.4 & 21 \\
\hline 2.0 & 0.021 & 2.4 & 16 & 0.040 & 2.4 & 60 & 0.045 & 1.1 & 21 & 0.33 & 6.5 & 20 \\
\hline 2.5 & 0.026 & 2.9 & 18 & 0.053 & 2.8 & 47 & 0.061 & 1.9 & 14 & 0.35 & 6.7 & 20 \\
\hline 3.0 & 0.032 & 4.4 & 18 & 0.072 & 3.6 & 41 & 0.071 & 2.2 & 15 & 0.44 & 7.2 & 17 \\
\hline
\end{tabular}

${ }^{a}$ Laser irradiation. ${ }^{b}$ After UV irradiation for $24 \mathrm{~h}$ while stirring.
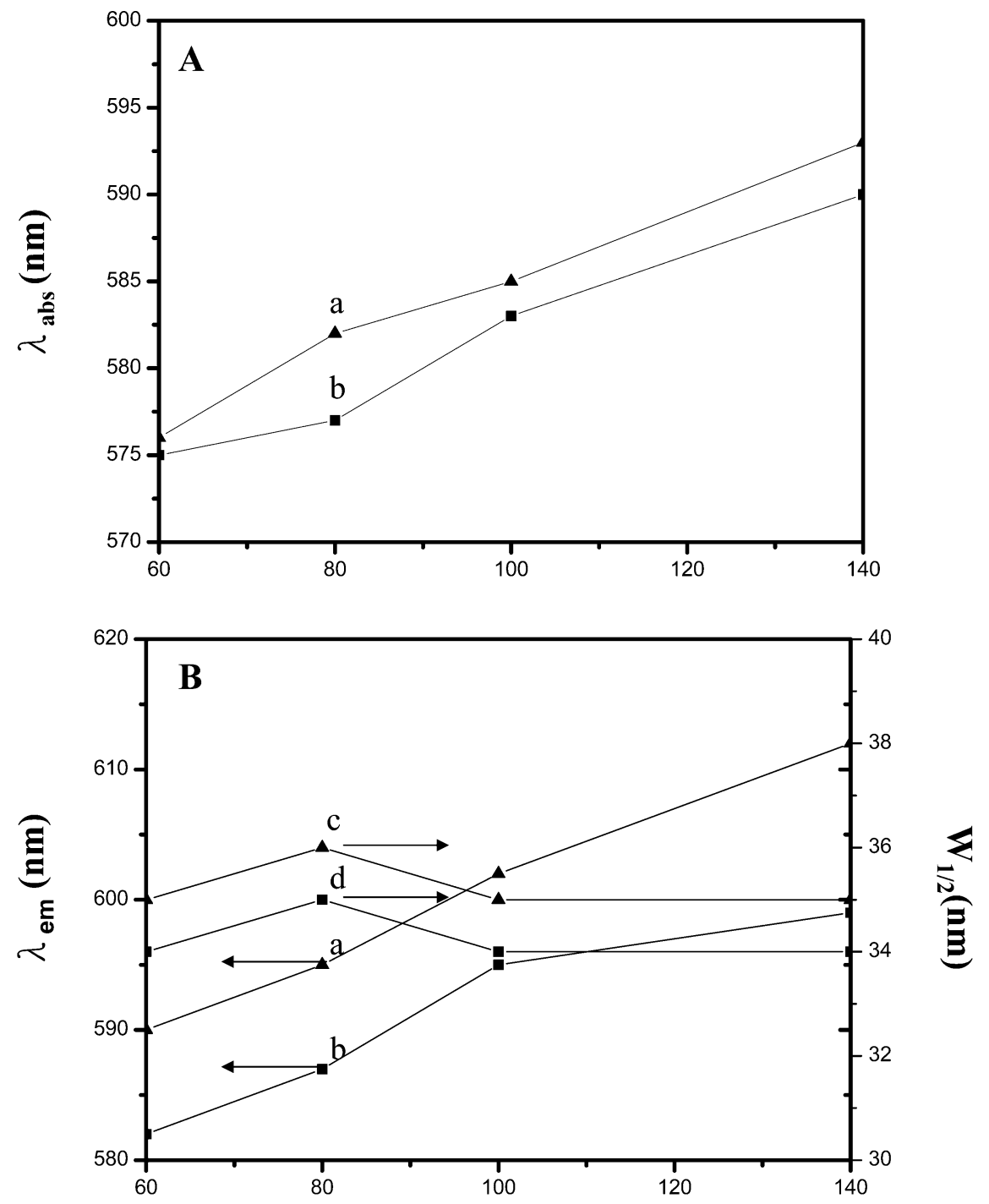

\section{Temperature $\left({ }^{\circ} \mathrm{C}\right)$}

Figure 3. Comparison of the optical properties of the core-shell CdSe/CdS QDs before and after UV irradiation for 24 h. (A) Absorption edge: curve a, before; b, after. (B) Emission wavelength: curve a, before; curve b, after; bandwidth: curve c, before; curve d, after. The CdSe QDs prepared after laser irradiation for $3 \mathrm{~h}$ were used as a representative sample.

the QY of the core-shell CdSe/CdS QDs is ca. 20 times that of the bare CdSe QDs. ${ }^{24}$ Using the same experimental (passivation) conditions, we used the $\mathrm{CdSe}(60), \mathrm{CdSe}(80)$ $\mathrm{CdSe}(100)$, and $\mathrm{CdSe}(140)$ QDs separately to prepare core-shell CdSe/CdS QDs. Figure 3A (curve a) and 3B (curve a) indicates that the core-shell CdSe/CdS QDs possess different optical properties, such as their absorption edges and maximum PL wavelengths. Relative to their corresponding CdSe QDs, the absorption edge and the PL wavelength for the core-shell CdSe/CdS QDs both shift to the red, with the maximum PL wavelength shift of $24 \mathrm{~nm}$ for the core-shell CdSe(140)/CdS QDs, and their QYs increase up to $7.2 \%$, with a maximum 136-fold improvement for the core-shell CdSe(60)/CdS QDs. Passivation has greater effects on the optical properties (QY) and a greater decrease in the trapping states (PL centered at $720 \mathrm{~nm}$ ) for the CdSe QDs prepared at low temperature. The shift (27 nm for core-shell CdSe(80)/ CdS QDs) in the PL maximum wavelength is greater than that ( $5 \mathrm{~nm}$ ) of the core-shell CdSe/CdS QDs formed using 


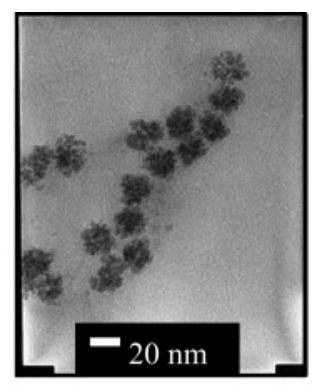

(A)

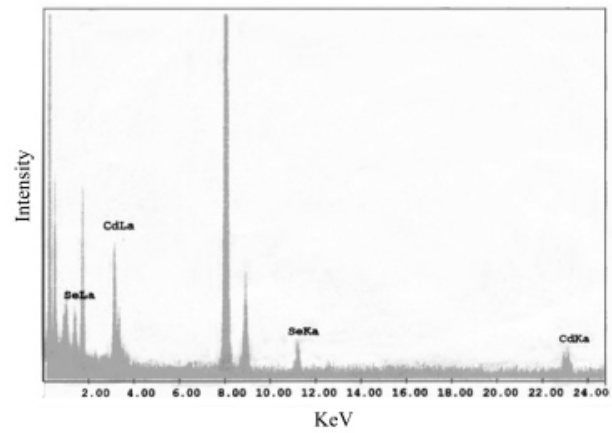

(C)

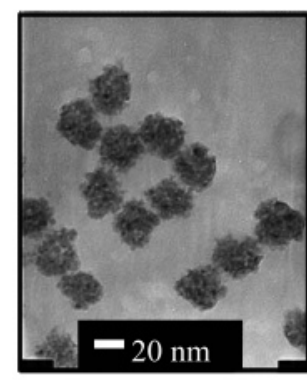

(B)

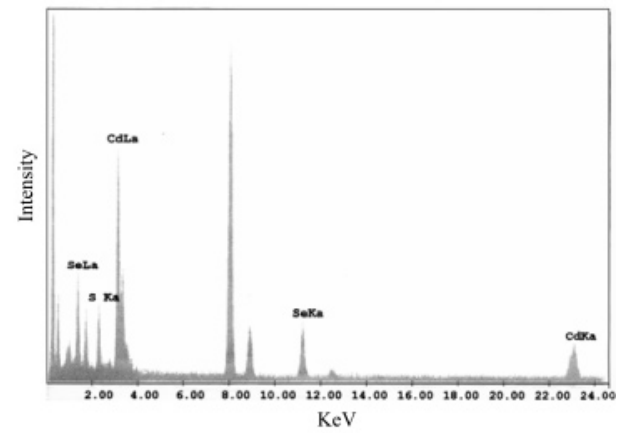

(D)

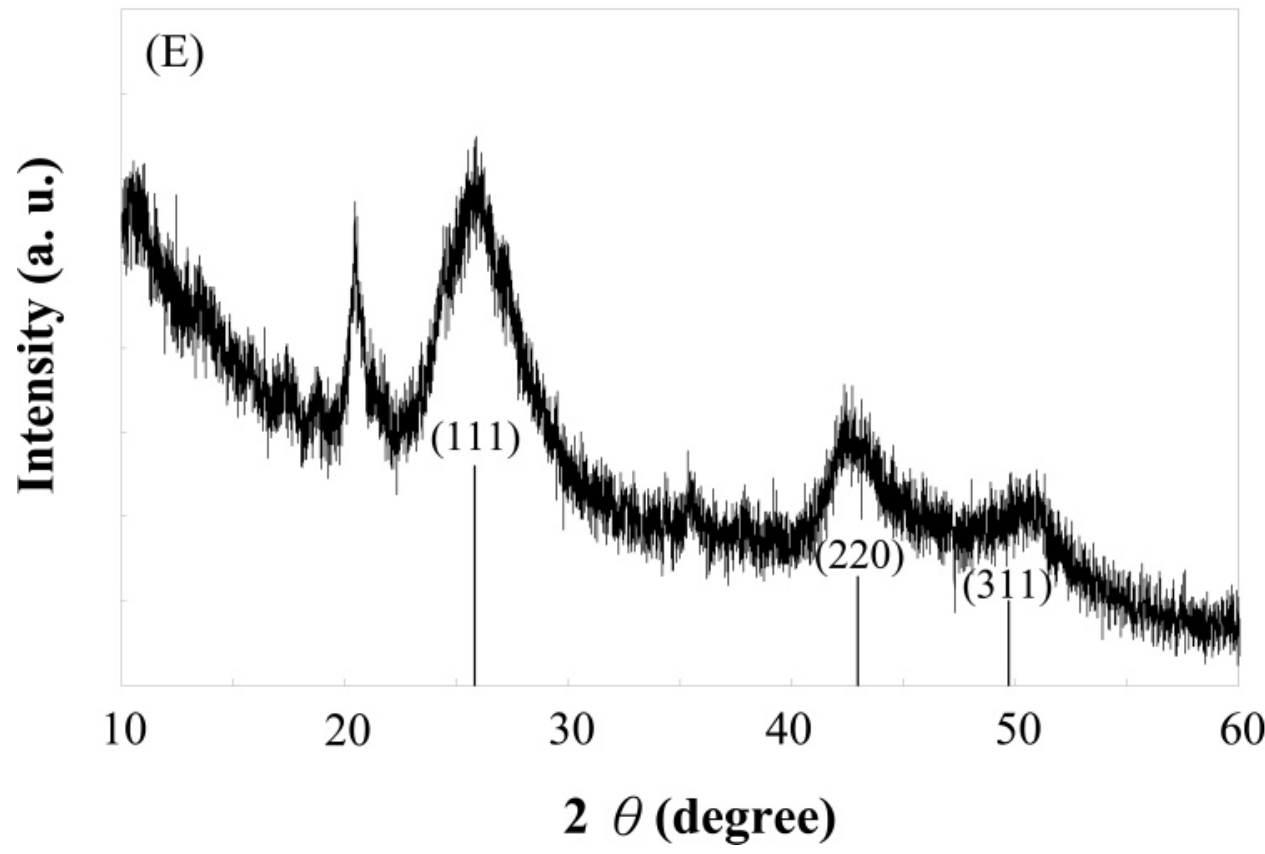

Figure 4. (A) and (B) TEM images of CdSe QDs and core-shell CdSe/CdS QDs, respectively. (C) and (D) EDX spectra of CdSe QDs and core-shell CdSe/CdS QDs, respectively. (E) XRD pattern of core-shell CdSe/CdS QDs. The CdSe QDs were synthesized at $80{ }^{\circ} \mathrm{C}$ while irradiating with laser light for $3 \mathrm{~h}$. The core-shell CdSe/CdS QDs without UV irradiation were used.

CdSe prepared under microwave heating (results not shown), which indicates that the shell is thicker in this study. Our reasoning is supported by the TEM images (Figure 4A and 4B), which show that the average size of the core-shell CdSe/CdS QDs is $5.0 \pm 0.3 \mathrm{~nm}$, with an average shell of $1.5 \mathrm{~nm}$, which is thicker than that $(0.7$ $\mathrm{nm}$; not shown) of the core-shell CdSe/CdS QDs formed using CdSe prepared under microwave heating. The EDX spectra (Figure 4C and 4D) represent the synthesized CdSe and core-shell CdSe/CdS QDs, respectively. For the asprepared core-shell CdSe/CdS QDs, the S:Se ratio is 0.7 , while the Cd:Se ratio of 1.7 is close to the value of 1.6 of the Cd/Se QDs. The XRD pattern (Figure 4E) of the asprepared core-shell CdSe/CdS particles is very much like that of the zinc blended phase CdSe/CdS particles. Because the main peak at ca. $25^{\circ}$ is likely to represent a small concentration of wurtzite $\mathrm{CdSe} / \mathrm{CdS}$, we used the peak at ca. $42^{\circ}$ to calculate the coherence length. The coherence length $(4.2 \pm 0.3 \mathrm{~nm})$, which we calculated from nine XRD spectra recorded using three different batches of coreshell CdSe/CdS QDs, is close to the value $(5.0 \pm 0.3 \mathrm{~nm})$ measured by analyzing the TEM images.

Photoetching is an effective method for improving $\mathrm{PL}$ QYs for several QDs, including CdS, core-shell CdSe/ CdS, ZnS: $\mathrm{Mn}^{2+}$, and others. ${ }^{33,34,36,37}$ The absorption and PL spectra depicted in Figure 3A (curve b) and 3B (curve

(36) Bol, A. A.; Meijerink, A. J. Phys. Chem. B 2001, 105, 10203.

(37) Cherniavskaya, O.; Chen, L.; Islam, M. A.; Brus, L. Nano Lett. 2003, 3, 497. 


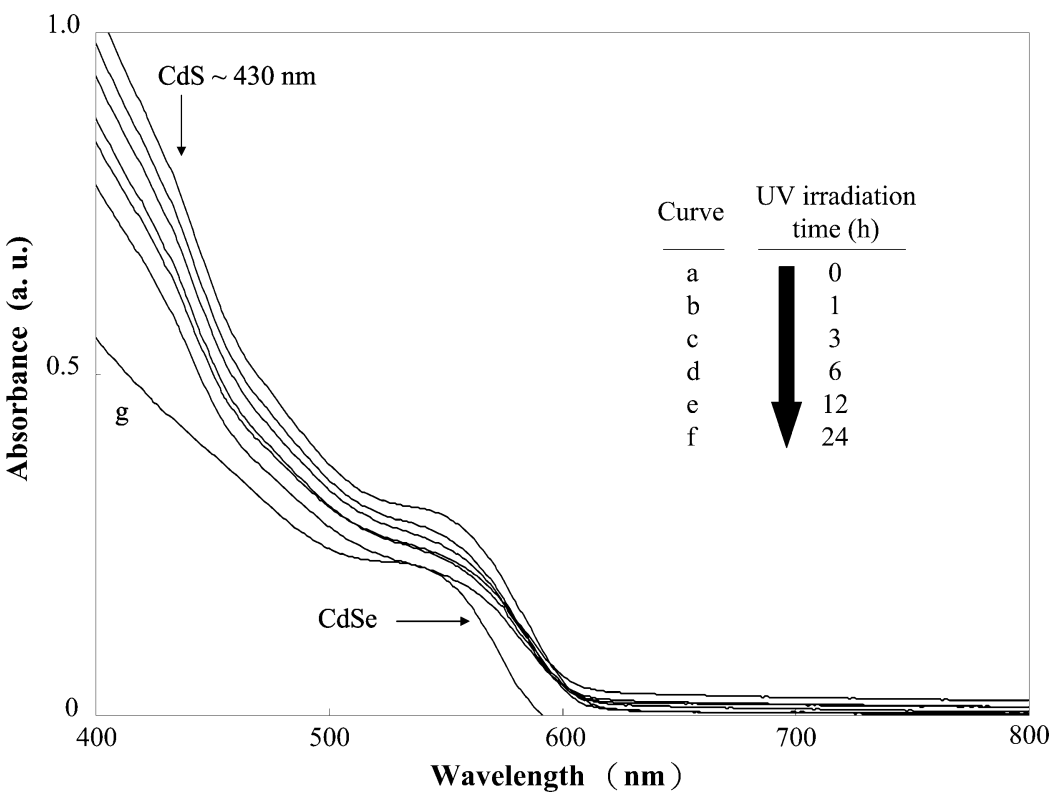

Figure 5. The absorption spectra of the core-shell CdSe(80)/CdS QDs and CdSe(80). Curves a-f represent the absorption spectra of the core-shell CdSe(80)/CdS QDs under UV irradiation for 0-24 h. Curve g represents the absorption spectrum of CdSe(80) QDs.

Table 2. The Effect that the Intensity of Light Has on the Preparation of the CdSe and Core-Shell CdSe/CdS QDs at 80 ${ }^{\circ} \mathrm{C}$ while Irradiating with Laser Light for $2 \mathrm{~h}$

\begin{tabular}{|c|c|c|c|c|c|c|c|c|c|}
\hline \multirow[b]{2}{*}{ laser power (mW) } & \multicolumn{3}{|c|}{$\mathrm{CdSe}$} & \multicolumn{3}{|c|}{$\mathrm{CdSe} / \mathrm{CdS}$} & \multicolumn{3}{|c|}{$\mathrm{CdSe} / \mathrm{CdS}^{a}$} \\
\hline & $\lambda_{\mathrm{em}}(\mathrm{nm})$ & $W_{1 / 2}(\mathrm{~nm})$ & $\mathrm{QY}(\%)$ & $\lambda_{\mathrm{em}}(\mathrm{nm})$ & $W_{1 / 2}(\mathrm{~nm})$ & $\mathrm{QY}(\%)$ & $\lambda_{\mathrm{em}}(\mathrm{nm})$ & $W_{1 / 2}(\mathrm{~nm})$ & $\mathrm{QY}(\%)$ \\
\hline 15 & 580 & 40 & 0.012 & 613 & 32 & 1.8 & 603 & 39 & 27 \\
\hline 50 & 577 & 40 & 0.040 & 605 & 33 & 2.4 & 597 & 33 & 60 \\
\hline 100 & 581 & 37 & 0.044 & 600 & 33 & 2.4 & 596 & 33 & 82 \\
\hline
\end{tabular}

a After 24-h UV irradiation under stirring.

b) display the absorption edge and PL maximum wavelength for the core-shell CdSe/CdS QDs after UV irradiation for $24 \mathrm{~h}$. The absorption edge and $\mathrm{PL}$ both undergo blue shifts, indicating that photoetching takes place. Evidence for photoetching is also provided by the observation of narrower PL bands (Figure 3B, curves c and d) after UV irradiation. Narrow bandwidths (fwhm $<35 \mathrm{~nm}$ ) indicate that the size distributions of the asprepared core-shell CdSe/CdS QDs are small. The increases in QY (Table 1) after UV irradiation (3- to 30fold) suggest that passivation of the surface occurred at pH 9.0 in the presence of excess amounts of $\mathrm{Cd}^{2+}$ in the solution during UV irradiation. ${ }^{30} \mathrm{PL}$ quantum yields as high as 60\% for the core-shell CdSe/CdS QDs have been achieved and their PL QY, peak position, and fwhm do not change detectably upon aging in air for several months (>6 months). The PL QYs of the CdSe/CdS prepared from CdSe QDs obtained at high temperature are not always greater than those exhibited by the CdSe QDs, which demonstrates again that surface structure/reconstruction occurs under UV irradiation.

To provide further evidence for photoetching, Figure 5 depicts the evolution of the absorption spectra for the coreshell $\mathrm{CdSe}(80) / \mathrm{CdS}$ QDs under UV irradiation. The absorption edge gradually shifts to blue $(582 \rightarrow 572 \mathrm{~nm})$ during photoetching $(24 \mathrm{~h})$, which indicates that the particle size decreases, and the absorption at $430 \mathrm{~nm}$ (corresponding to the absorption of $\mathrm{CdS}$ ) decreases with increasing time, which is strong evidence that the photooxidation of CdS occurs. The change in absorption is greater for the as-prepared core-shell CdSe(80)/CdS QDs when the $\mathrm{CdSe}(80) \mathrm{QD}$ s were prepared under shorter laser irradiation times. This phenomenon may be due to the instability of the CdSe surface or the inefficient passivation of CdSe by CdS. Our reasoning is supported partially by the decreases in the $\mathrm{S}: \mathrm{Se}(0.7 \rightarrow 0.6)$ and $\mathrm{Cd}: \mathrm{Se}(1.6 \rightarrow 1.4)$ ratios obtained from the EDX data after the photoetching reaction and by the sharper XRD peak profiles.

Effect of Laser Power. To test the dependence that the intensity of the laser light has on the preparation of the CdSe and core-shell CdSe/CdS QDs, lasers having powers of 15 and $100 \mathrm{~mW}$ were also used to irradiate the samples during the synthesis at $80^{\circ} \mathrm{C}$. The small variations of the emission wavelengths for the CdSe QDs listed in Table 2 indicate that the laser power does not affect the particle sizes significantly, which is a result that is in good agreement with that obtained from the TEM images (mean size diameters are $3.5 \pm 0.4 \mathrm{~nm}$ ). The main feature of using a high-power laser to prepare the $\mathrm{QDs}$ is to provide a greater QY, which arises mainly because the size distribution is smaller and because there are fewer defects on the surface of the QDs. Our reasoning is supported by the fact that the QDs prepared under laser irradiation of $100 \mathrm{~mW}$ possess a smaller value of $W_{1 / 2}$, a smaller blue shift in the emission after UV photobleaching, and sharp, symmetric peak profiles in the XRD spectrum (not shown).

PL of Various Core-Shell CdSe/CdS QDs. It has been shown that the size and, thus, the PL can be tuned by simply changing the ratio of the precursors. ${ }^{9,24}$ At high $\mathrm{Cd}$ :Se ratios, a greater number of CdSe seeds form, which, as a result, decreases the sizes of the prepared CdSe QDs. Figure 6 indicates that this simple photoassisted method allows the preparation of core-shell CdSe/CdS QDs that have maximum PL wavelengths $\left(\lambda_{\mathrm{em}}\right)$ ranging from 560 $\mathrm{nm}$ (green) to $615 \mathrm{~nm}$ (red) when using the $\mathrm{Cd}$ and Se precursors at initial Cd:Se concentration ratios from 12 to 2 , respectively. From the TEM images (data not presented), the sizes of the as-prepared QDs are $3.7 \pm 0.6$, 


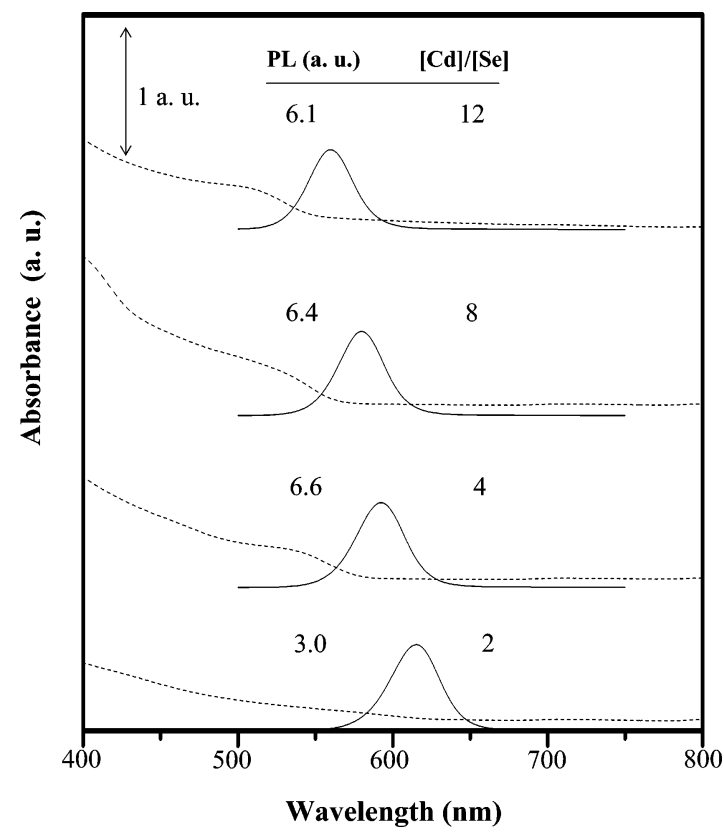

Figure 6. Absorption and PL spectra of the core-shell CdSe/ CdS QDs prepared under different experimental conditions. The dotted and solid curves represent the absorption and PL $\left(\lambda_{\text {ex }}=480 \mathrm{~nm}\right)$ spectra, respectively. Absorbance units and arbitrary units are represented by the abbreviation "a. u." in the absorption and PL spectra, respectively.

$4.2 \pm 0.3,4.9 \pm 0.5$, and $6.3 \pm 1.2 \mathrm{~nm}$ when the $\mathrm{Cd}: \mathrm{Se}$ concentration ratios are $12,8,4$, and 2 , respectively. The PL QYs of the CdSe(80)/CdS QDs prepared by this method are 55, 57, 60, and $23 \%$ when the Cd:Se concen- tration ratios were $12,8,4$, and 2 , respectively. The trend of decreasing $\mathrm{PL} Q \mathrm{QY}$ and increasing QD size with decreasing $\mathrm{Cd} / \mathrm{Se}$ ratio is in good agreement with that reported by $\mathrm{Qu}$ and Peng, ${ }^{9}$ who have suggested that a significant excess of one of the precursors promotes the formation of CdSe QDs having a high PL QY because it provides a desirable condition for the construction of the most favorable surface structure/reconstruction for the nanoparticles in the solution.

Conclusions. Here, we present a simple synthetic route to the preparation of high-quality CdSe QDs in aqueous solution. The thermal synthesis, assisted by laser irradiation at $532 \mathrm{~nm}$, allows the preparation of CdSe QDs that possess higher PL QY and narrower values of fwhm relative to those of the corresponding QDs prepared by microwave heating. After UV irradiation, the as-prepared core-shell CdSe/CdS QDs become stable and fluoresce strongly in the visible range. By controlling the Cd:Se concentration ratio, this approach allows the synthesis of $\mathrm{CdSe} / \mathrm{CdS}$ QDs with the sizes of 3.7-6.3 $\mathrm{nm}$ in diameter that emit in a wide range in the visible region (green to red). The as-prepared CdSe/CdS QDs are stable, highly fluorescent, and should be useful for biological applications after suitable modification.

Acknowledgment. This work was supported by the National Science Council of Taiwan under contract number NSC 92PFA0100100. We thank Messrs. ChingYen Lin and Chih-Yuan Tang from the Instrumentation Center of National Taiwan University for developing the TEM pictures.

LA049489Q 